\title{
Characteristics of rainfall during tropical cyclone periods in Taiwan
}

\author{
K. K. W. Cheung ${ }^{1}$, L.-R. Huang ${ }^{2}$, and C.-S. Lee ${ }^{2}$ \\ ${ }^{1}$ Climate Risk Concentration of Research Excellence and Department of Physical Geography, Macquarie University, \\ Sydney, Australia \\ ${ }^{2}$ Department of Atmospheric Sciences, National Taiwan University, Taiwan
}

Received: 8 August 2008 - Revised: 18 November 2008 - Accepted: 18 November 2008 - Published: 23 December 2008

\begin{abstract}
Due to the Central Mountain Range with an elevation up to about $4 \mathrm{~km}$, the amount and distribution of rainfall in Taiwan associated with typhoons or tropical cyclones (TCs) depends not only on the distribution of convection within the TCs (internal structure) and influences from monsoon-scale environmental flow, but also on the orographic effect. This study analyzes the spatial and temporal characteristics of rainfall associated with $62 \mathrm{TC}$ cases that affected Taiwan by using observations from the 371 automatic rain stations available in the period 1989-2002. It is found from the climatology maps that highly different rainfall distributions occurred for TCs that approached the Taiwan area from different directions. By performing objective clustering analysis of the rainfall time series of all the rain gauges, several characteristic temporal rainfall profiles are obtained. The geographic distribution of rain gauges that possess a particular temporal profile is also consistent with the possible TC track types that bring maximum rain to the Taiwan area at different times.

Based on data in the 1989-2002 period, the development of a TC rainfall climatology-persistence (CLIPER) model is described. CLIPER is an optimized combination of climatology and persistence with different relative weighting for different forecast periods. Independent cases (other than the model development database) during 2003-2004 are used to validate the model. Objective measures like equitable threat score and bias score show that CLIPER's skill is acceptable for practical applications for 24-h rain threshold below $100 \mathrm{~mm}$. However, the underestimation bias for more heavy rainfall is serious and CLIPER seems to have better performance for the northwestern Taiwan than for the other locations. Future directions for improvement of the CLIPER model are discussed.
\end{abstract}

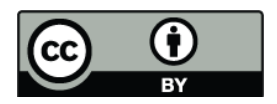

Correspondence to: K. K. W. Cheung (kcheung@els.mq.edu.au)

\section{Introduction}

Impact from typhoons or tropical cyclones (TCs) is one of the major natural hazards to the coastal cities in Southeast Asia and in particular to Taiwan. According to the records of issuing typhoon sea and land warnings from the Central Weather Bureau (CWB) of Taiwan in the period 1961-2004, an average number of nearly five TCs affected Taiwan every year and nearly two made landfall. About $74 \%$ of these TCs occurred during July-September. Some of the most disastrous cases include Typhoon Herb (1996), Typhoon Zeb (1998), Typhoon Billis (2000), Typhoons Toraji and Nari (2001) and Typhoon Mindulle (2004). In particular, Typhoon Nari stayed over land of Taiwan for $51 \mathrm{~h}$ and brought $1.051 \mathrm{~mm}$ of total rainfall to Taipei City. Sometimes, the difficulty in forecasting rainfall associated with TCs was further increased by the fact that heavy rainfall was brought by monsoonal flows enhanced or modified by the TC circulation. A recent example is Typhoon Mindulle (2004) that was accompanied by strong Asian summer monsoonal southwesterlies and resulted in large amount of rainfall in the southwest area of Taiwan (Lee et al., 2006). Therefore, improving the skill of rainfall prediction from the short range (1-12 h) up to 3 days becomes a major target for the Taiwan local forecasters and personnel in hazard mitigation organizations such as the National Science and Technology Center for Disaster Reduction (NCDR).

Although understanding and predicting the physical processes when a TC makes landfall (including precipitation) has become the focus of some major research programs such as the "Hurricane Landfall" project in the US Weather Research Program (Elsberry, 2005), it is generally recognized that the progress in improving TC intensity forecast and quantitative precipitation forecast has been slow. Recent studies indicated that some high-resolution (as fine as $\sim 2 \mathrm{~km}$ ) dynamical model simulations were capable of capturing roughly the rainfall pattern for scales as small as the

Published by Copernicus Publications on behalf of the European Geosciences Union. 
Taiwan island (e.g., Wu et al., 2002; Chiao and Lin, 2003). However, the maximum accumulated rainfall was sometimes not well simulated and the skill of forecasts varied from time to time, which reduced greatly the value of these numerical products in hazard mitigation applications. Before the skill of dynamical models is improved to an acceptable level for operational applications, forecasters usually rely on various statistical models for rainfall estimation and issuing warnings. The fact that the distributions of convection and rainfall in TCs have certain characteristic patterns both when they are over open oceans (Lonfat et al., 2004) and when making landfall (Chan et al., 2004) allows the application of statistical descriptions and predictions based on climatology. For instance, Lonfat et al. (2004) found from microwave imageries that generally the maximum rainfall of a TC is located in the front quadrants (relative to storm motion), and this location shifts from the front-left quadrant for weaker TCs to the front-right quadrant for stronger TCs. Based on satellite and radar observations of four TCs that made landfall along the south China coast in 1999, Chan et al. (2004) also found that stronger convection generally appeared in the front and then the left quadrant of a TC but vertical wind shear might influence the distribution of convection (Corbosiero and Molinari, 2002). The purpose of this study is to provide a detailed statistical analysis of the characteristics of TC-related rainfall in the Taiwan area and illustrate the skill level of a simple climatology-based statistical model for TC rainfall prediction.

The organization of this paper is as follows. In order to understand how the typhoon-related rainfall climatology is established, Sect. 2 first gives a brief description of the data used and the quality control processes. Section 3 provides statistical analyses of the spatial and temporal rainfall characteristics as well as some special rainfall patterns in which the East Asian monsoon system plays an important role. Section 4 describes the establishment of a statistical model for TC rainfall prediction based on climatology and persistence, and provides evaluation of the model forecast. The study is concluded with a summary and discussion in Sect. 5.

\section{Data}

Before 1989, the rainfall distribution in Taiwan was measured mainly by the 22 traditional weather stations over the island (Yeh, 2002). Although data from some of these stations have been available long enough (e.g., since the 1950's) for climate studies, extreme rainfall cannot be well captured by the coarse-resolution network. By 1989, the automatic rain gauge network was completed that made the total number of rain stations to be 371 including several off-coast island stations (Fig. 1), and the number keeps increasing in recent years. As can be seen in the figure, the rain stations are quite uniformly distributed in the plain area but are less dense in the Central Mountain Range (CMR). However, tor-

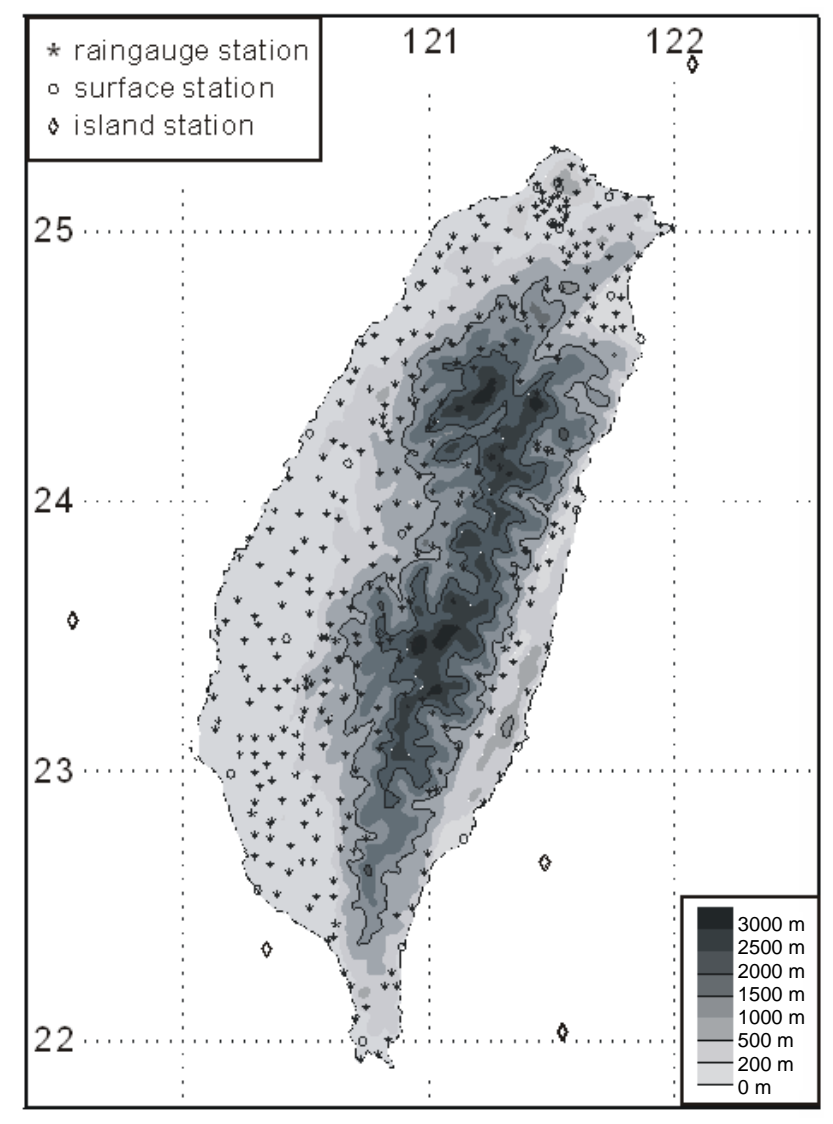

Fig. 1. Locations of the 371 rainfall stations in Taiwan. The contours mark topography with heights $1 \mathrm{~km}$ and $2 \mathrm{~km}$ respectively.

rential rains occur over the CMR are frequently enhanced by orographic lifting. When such an effect is present, the rain amount is often very high and its distribution also greatly affected by topography. Thus the rain stations at the mountain area are important to capture the peak rain rate. Data from these 371 rain stations are updated every ten minutes and they are sent automatically through a radio wireless network into the CWB.

Sometimes, rain gauges have malfunction periods that indicate simply a zero reading. Therefore, a quality control procedure is carried out for all rain data used in the study. The temporal rain profiles of all the rain stations during TC periods are examined. When some unusual periods of zero rain are encountered, data from other stations in the vicinity are checked. If the accumulated rain of the problematic station is still similar to the nearby stations (i.e., data is only missing in a short period), then the data during the period with zero reading is replaced manually with data from the nearest station after scaling by the ratio of accumulated rains of those two stations in the entire TC period. Otherwise, if the accumulated rain of the problematic station is zero or very low, the station in that particular TC period is treated as missing data. Note also that in this quality control procedure, 
care is taken to compare data from stations at different altitudes because orographic effect sometimes generates rain in a mountainous area but not in a nearby plain area.

\section{Characteristics of TC-related rainfall in Taiwan}

\subsection{Tropical cyclone tracks}

Except for a few tropical storms that brought little rain to the Taiwan area, 61 TCs during 1989-2002 are considered in this study. The tracks of TCs that affected the Taiwan area can roughly be divided into two categories: east-west (E-W) oriented and south-north (S-N) oriented. The E-W tracks consist of 34 TCs during 1989-2002 that formed in the monsoon trough region east of the Philippines or central North Pacific and then migrated westward (Fig. 2a). Nearly half of these TCs made landfall to the Taiwan main island. A peculiar case is Typhoon Nat (1991) that made landfall at the southern tip of Taiwan and entered the South China Sea (SCS). However, after a looping path it re-intensified and moved northward again. The CWB issued two separate warning periods for Nat, and it is also treated as two separate cases when its rainfall is analyzed in this study (and hence the total number of cases is 62, see Table 1). On the other hand, the S-N cases consist of $27 \mathrm{TCs}$ in the same period that formed in either the western North Pacific (WNP) or SCS, and then migrated northward (Fig. 2b). There is also an exceptional case in this category. Typhoon Nari (2001) formed at about 400-500 km northeast of Taiwan, moved southwestward and then made landfall at northern Taiwan, which is the only case with a southward component of movement in the period.

\subsection{Spatial characteristics}

The spatial characteristics of TC rainfall is studied by first setting up climatology based on the $62 \mathrm{TC}$ cases. The domain used for study is $118^{\circ}-126^{\circ} \mathrm{E}, 18^{\circ}-27^{\circ} \mathrm{N}$, with grid size $0.5^{\circ} \times 0.5^{\circ}$ latitude/longitude. When one of the $62 \mathrm{TC}$ tracks passes through one of the grids in the domain (based on hourly positions interpolated from the best tracks), the rainfall data of the 371 rain gauges are recorded. Thus after examining all $62 \mathrm{TC}$ cases, statistics on the average, maximum and minimum rainfall, standard deviation and the number of TCs ever passed through each grid box and for each rain gauge are obtained. In other words, for each rain gauge there is a map of rainfall describing the climatology of that particular station when a TC is situated at different position in the domain (Fig. 3). For example, Fig. 3 indicates that Taipei station (46692) will be receiving more rainfall when the TC center is located northeast of Taiwan or over land west of the CMR. In order to refine the rainfall map so that rainfall estimation for localized regions in Taiwan can be provided, the climatology within the $0.5^{\circ} \times 0.5^{\circ}$ latitude/longitude grid boxes are further inter-

\section{(a) Typhoon Tracks 1989-2002 (E-W)}

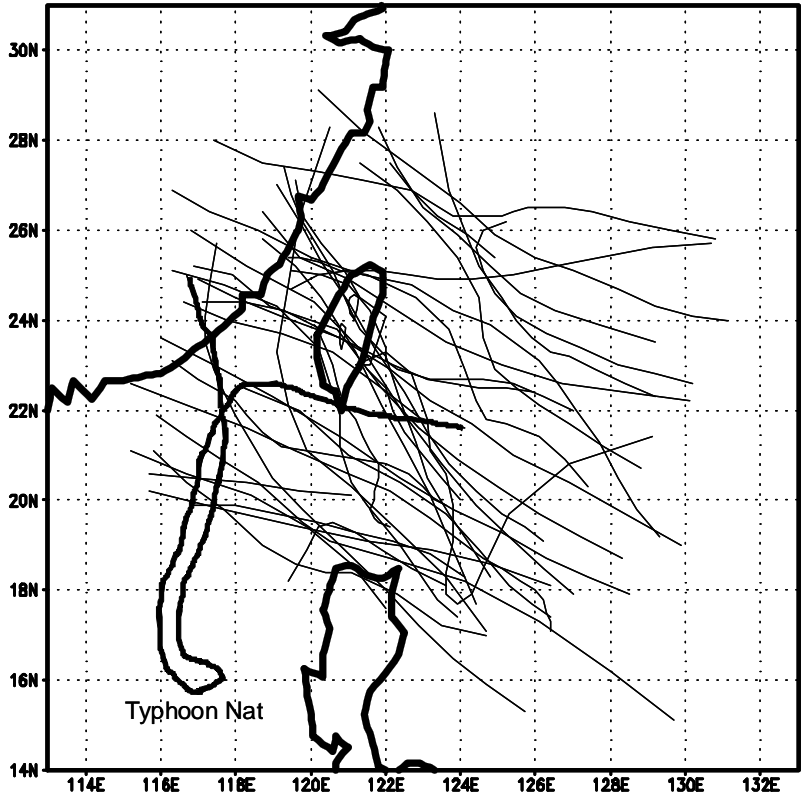

(b) Typhoon Tracks 1989-2002 (S-N)

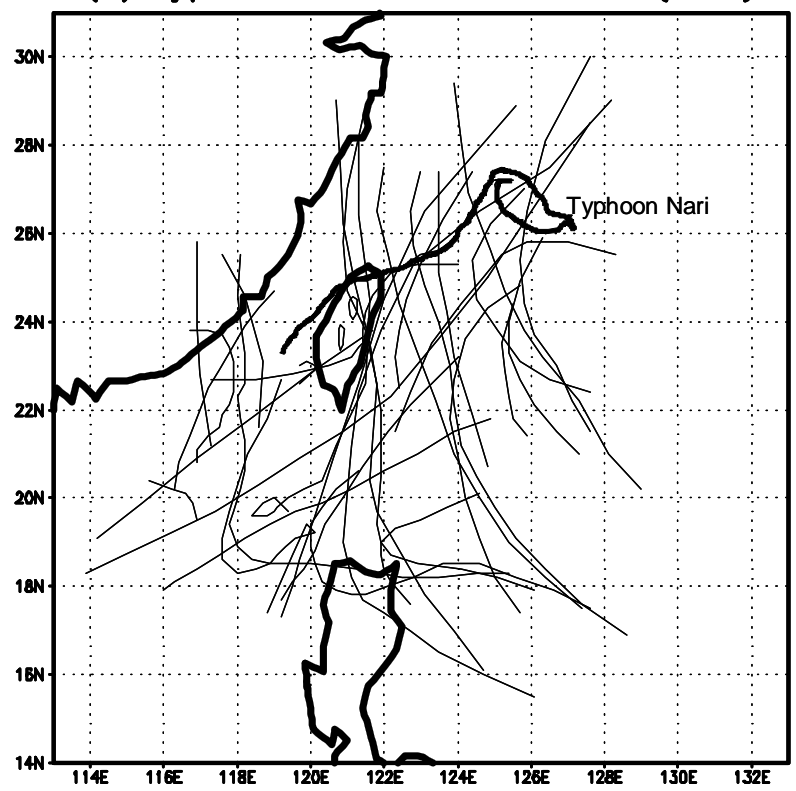

Fig. 2. The (a) 34 east-west oriented and (b) 27 south-north oriented TC tracks during 1989-2002 in the Taiwan area. Note the special track types of Typhoons Nat (1991) and Nari (2001).

polated to $0.1^{\circ} \times 0.1^{\circ}$ latitude/longitude grid boxes using the Barnes objective analysis (Barnes, 1973).

To obtain a simple picture of TC rainfall climatology over Taiwan, the climatological maps within $2^{\circ} \times 2^{\circ}$ latitude/longitude grids of the original domain are averaged and the resulting maps are placed according to the relative position of the involved TCs to the Taiwan island (Fig. 4, see also Chang et al., 1993). 
Table 1. List of the 62 TC cases in the rainfall climatology database. Time shown for the land warning period is local time that is $8 \mathrm{~h}$ ahead of UTC.

\begin{tabular}{|c|c|c|c|}
\hline Year & CWB TC Number & Name & Land Warning Period (LTC) \\
\hline 1989 & 19 & Sarah & 15:00 L 8 Sep-15:20 L 13 Sep \\
\hline 1990 & 03 & Marian & 15:40 L 18 May-14:50 L 19 May \\
\hline 1990 & 05 & Ofelia & 21: 30L 21 Jun-04:30 L 24 Jun \\
\hline 1990 & 06 & Percy & 04:10 L 27 Jun-15:10 L 29 Jun \\
\hline 1990 & 12 & Yancy & 04:40 L 18 Aug-04:15 L 20 Aug \\
\hline 1990 & 14 & Abe & 16:15 L 29 Aug-03:45 L 31 Aug \\
\hline 1990 & 17 & Dot & 16:00 L 6 Sep-21:10 L 8 Sep \\
\hline 1991 & 07 & Amy & 09:45 L 17 Jul-21:10 L 19 Jul \\
\hline 1991 & 11 & Ellie & 15:15 L 16 Aug-15:45 L 18 Aug \\
\hline 1991 & 20 & Nat (1) & 15:10 L 22 Sep-21:10 L 23 Sep \\
\hline 1991 & 20 & Nat (2) & 15:50 L 30 Sep-06:30 L 2 Oct \\
\hline 1991 & 23 & Ruth & 09:35 L 29 Oct-09:30 L 30 Oct \\
\hline 1992 & 02 & Bobbie & 21:10 L 26 Jun-15:40 L 28 Jun \\
\hline 1992 & 15 & Omar & 21:55 L 3 Sep-15:00 L 5 Sep \\
\hline 1992 & 16 & Polly & 15:30L 27 Aug-09:40L 31 Aug \\
\hline 1992 & 19 & Ted & 15:20 L 20 Sep-09:30 L 23 Sep \\
\hline 1993 & 11 & Tasha & 03:30 L 18 Aug-21:00 L 18 Aug \\
\hline 1993 & 14 & Yancy & 09:15 L 1 Sep-09:00 L 2 Sep \\
\hline 1993 & 16 & Abe & 15:45 L 11 Sep-21:30L 12 Sep \\
\hline 1994 & 05 & Tim & 15:00 L 9 Jul-15:40 L 11 Jul \\
\hline 1994 & 12 & Caitlin & 08:30 L 3 Aug-14:30 L 4 Aug \\
\hline 1994 & 13 & Doug & 14:30 L 6 Aug-06:15 L 9 Aug \\
\hline 1994 & 15 & Fred & 14:40 L 19 Aug-05:50 L 22 Aug \\
\hline 1994 & 16 & Gladys & 10:15 L 31 Aug-02:30 L 2 Sep \\
\hline 1994 & 27 & Seth & 20:40 L 7 Oct-20:40 L 10 Oct \\
\hline 1995 & 02 & Deanna & 05:40 L 8 Jun-14:50 L 8 Jun \\
\hline 1995 & 09 & Kent & 03:20 L 30 Aug-05:40 L 31 Aug \\
\hline 1995 & 15 & Ryan & 20:325 L 1 Sep-03:40 L 23 Sep \\
\hline 1996 & 03 & Cam & 03:20 L 22 May-11:50 L 23 May \\
\hline 1996 & 07 & Gloria & 15:15 L 24 Jul-15:30 L 27 Jul \\
\hline 1996 & 08 & Herb & 23:20 L 29 Jul-23:20 L 1 Aug \\
\hline 1996 & 18 & Sally & 15:10 L 7 Sep-11:45 L 8 Sep \\
\hline 1997 & 14 & Winnie & 05:20 L 17 Aug-23:45 L 18 Aug \\
\hline 1997 & 17 & Amber & 20:40 L 27 Aug-23:40 L 29 Aug \\
\hline 1997 & 19 & Cass & 10:00 L 30 Aug-20:20 L 30 Aug \\
\hline 1997 & 26 & Ivan & 20:25 L 19 Oct-17:10 L 21 Oct \\
\hline 1998 & 01 & Nichole & 05:55 L 9 Jul-09:45 L 10 Jul \\
\hline 1998 & 02 & Otto & 14:55 L 3 Aug-09:00 L 5 Aug \\
\hline 1998 & 09 & Yanni & 23:30 L 27 Sep-08:55 L 29 Sep \\
\hline 1998 & 10 & Zeb & 20:20 L 13 Oct-02:45 L 17 Oct \\
\hline 1998 & 12 & Babs & 08:50 L 26 Oct-23:05 L 27 Oct \\
\hline 1999 & 06 & Maggie & 08:40 L 5 Jun-20:45 L 6 Jun \\
\hline 1999 & 11 & Sam & 20 15L 19 Aug-23:26L 21 Aug \\
\hline 1999 & 20 & Dan & 20:45 L 7 Oct-20:10 L 9 Oct \\
\hline 2000 & 04 & Kaitak & 05:45 L 8 Jul-23:05 L 9 Jul \\
\hline 2000 & 10 & Bilis & 14:45 L 21 Aug-20:05 L 23 Aug \\
\hline 2000 & 12 & Prapiroon & $14: 45$ L 28 Aug-08:40 L 30 Aug \\
\hline 2000 & 15 & Bopha & 20:40 L 8 Sep-08:40 L 10 Sep \\
\hline 2000 & 19 & Yagi & 14:50 L 24 Oct-03:25 L 26 Oct \\
\hline 2000 & 20 & Xangsane & 02:45 L 31 Oct-17:45 L 1 Nov \\
\hline 2000 & 21 & Bebinca & 10:15 L 6 Nov-08:55 L 7 Nov \\
\hline 2001 & 01 & Cimaron & 20:35 L 11 May-17:50 L 13 May \\
\hline 2001 & 02 & Chebi & 08:10 L 22 Jun-05:35 L 24 Jun \\
\hline 2001 & 04 & Utor & 20:30 L 3 Jul-17:10 L 5 Jul \\
\hline 2001 & 05 & Trami & 20:15 L 10 Jul-21:00 L 11 Jul \\
\hline 2001 & 08 & Toraji & 11:10 L 28 Jul-14:35 L 31 Jul \\
\hline 2001 & 16 & Nari & 02:45 L 15 Sep-17:10 L 19 Sep \\
\hline 2001 & 19 & Lekima & 14:30 L 24 Sep-09:10 L 28 Sep \\
\hline 2001 & 21 & Haiyan & $14: 25$ L 15 Oct-17:30 L 16 Oct \\
\hline 2002 & 05 & Rammasun & 14:45 L 2 Jul-17:25 L 4 Jul \\
\hline 2002 & 08 & Nakri & 05:50 L 9 Jul-20:15 L 10 Jul \\
\hline 2002 & 16 & Sinlaku & 05:15 L 5 Sep-05:50 L 8 Sep \\
\hline
\end{tabular}

It can be seen that heavy rainfall occurred at the east coast of Taiwan when TCs were located at the south $\left(120^{\circ}-122^{\circ} \mathrm{E}\right.$,

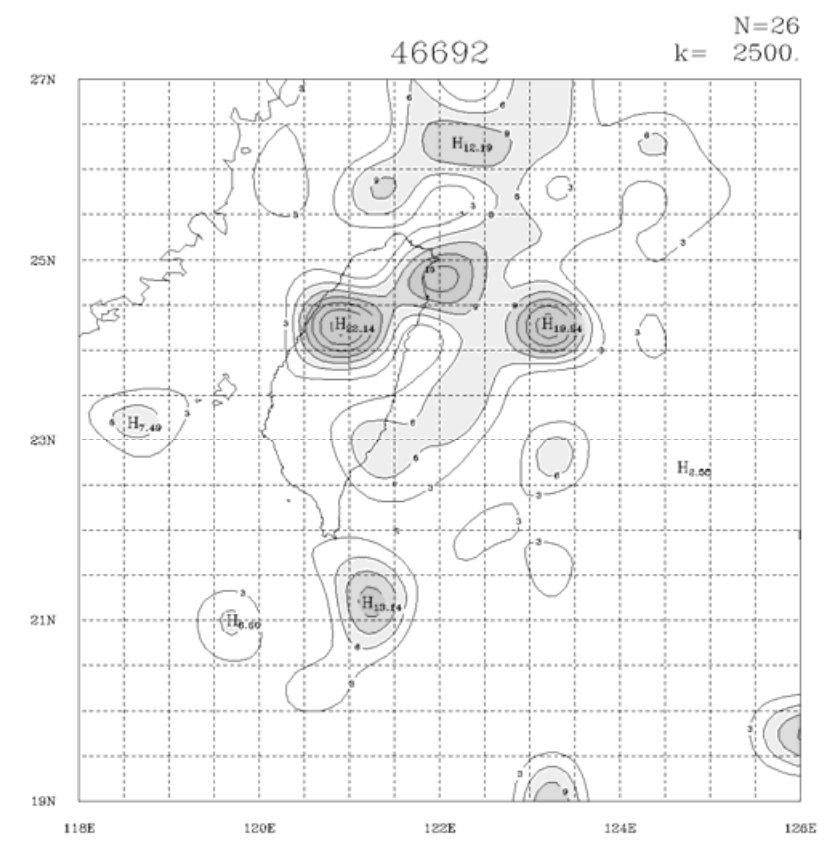

Fig. 3. Computation domain and the $0.5^{\circ} \times 0.5^{\circ}$ latitude/longitude grid boxes used in computing the statistics of TC rainfall during 1989-2002. The rainfall climatology map shown is for the Taipei station (46692) after a Barnes objective analysis to a fine $0.1^{\circ} \times 0.1^{\circ}$ latitude/longitude grid.

$\left.19^{\circ}-23^{\circ} \mathrm{N}\right)$ or southwest $\left(118^{\circ}-120^{\circ} \mathrm{E}, 19^{\circ}-21^{\circ} \mathrm{N}\right)$. In this situation, the eastern side of the CMR was under impact from the TC circulation and orographic lifting effect enhanced the rainfall there (Lin et al., 2002). However, the CMR also blocked the strong easterly winds of the cyclone from the west coast and thus less rainfall was obtained over there. When TCs made landfall and located in $120^{\circ}-122^{\circ} \mathrm{E}, 23^{\circ}-$ $25^{\circ} \mathrm{N}$, the rainfall distribution also concentrated on the east. Another situation with heavy TC rainfall was when the TC center located at northeast $\left(122^{\circ}-124^{\circ} \mathrm{E}, 25^{\circ}-27^{\circ} \mathrm{N}\right)$ of Taiwan. Large amount of rain fell on northwestern Taiwan because the TC circulation impinged directly on the northern part of the CMR and enhanced orographic lifting effect there. When the TC center was more to the west, the western side of the CMR also received large amount of rainfall as shown in the panel $120^{\circ}-122^{\circ} \mathrm{E}, 25^{\circ}-27^{\circ} \mathrm{N}$. Comparatively, the rainfall amount would be much less when the TC center was at other positions relative to the Taiwan island.

\subsection{Temporal characteristics}

Besides the accumulated rainfall amount, the temporal profile is also important in understanding the characteristics of rainfall brought by TCs. For this purpose, the hourly rain rate recorded at each of the 365 stations in Taiwan main island (i.e., the 6 off-coast island stations are neglected in this analysis) during the 62 TC impacts are averaged. Since the time 


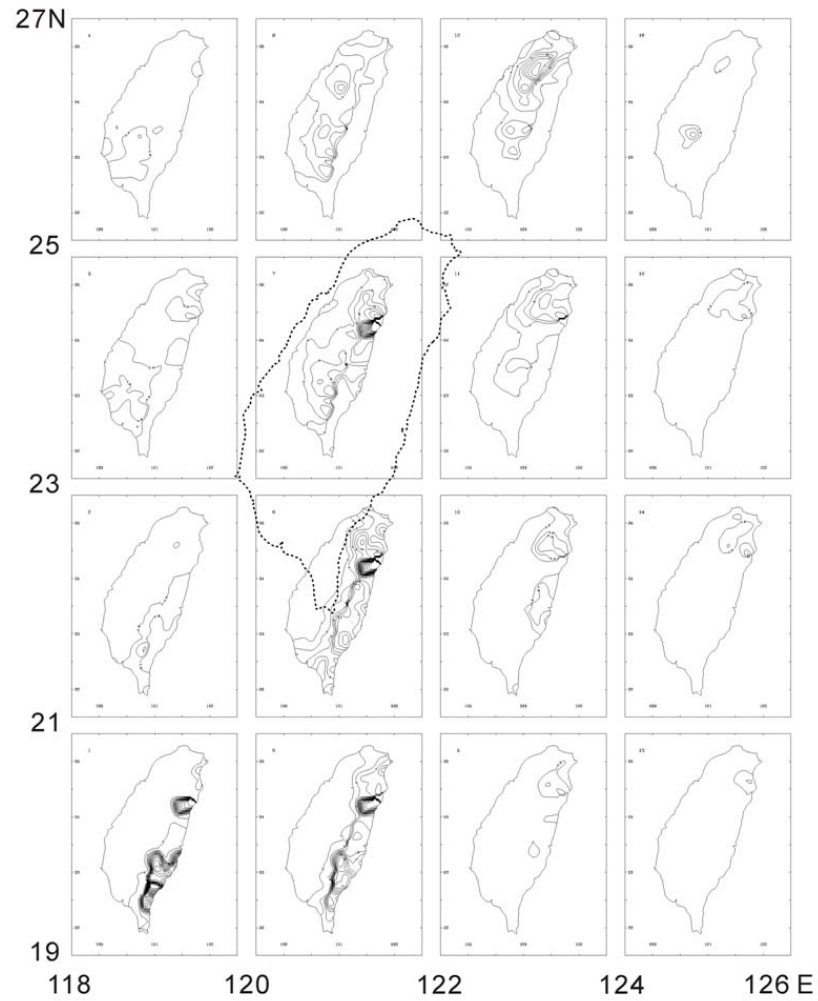

Fig. 4. TC rainfall climatology in the Taiwan area (contours shown are hourly rain rate with interval $2 \mathrm{~mm} \mathrm{~h}^{-1}$ ). Each $2^{\circ} \times 2^{\circ}$ latitude/longitude panel represents the distribution when the TCs are located in that panel relative to the central Taiwan map.

period of each TC affecting Taiwan (when the CWB typhoon warning was raised) is different, this time period and the associated rain data are first normalized to 100 time units before averaging. While a time unit for each of the TCs may be different, the rain rate $\left(\mathrm{mm} \mathrm{h}^{-1}\right)$ in each time unit is calculated such that data from different TCs can be compared. Then the 365 rain rate time series are input to a hierarchical clustering analysis with the correlation coefficient between two time series as their distance measure. Similar clusters result when using the single-linkage, complete-linkage or the average-distance-within-clusters methods of calculating distances between clusters, and the final results are based on the last one. When the correlation coefficient between two clusters drops to about 0.6 , six clusters remain that are physically meaningful when considering the locations of the cluster members (to be discussed later). The number of members for the six clusters is respectively $52,117,5,33,96$, and 62 .

The five rain profiles (except cluster number 3 ) obtained by the clustering analysis show two typical characteristic temporal patterns of TC rainfall affecting Taiwan (Fig. 5). One has heavier rainfall with the peak rain rate occurred earlier (cluster 4 and cluster 5). The other one has the rain rate increasing gradually with peak rain rate occurred near the end of the TC period (clusters 1, 2 and 6). Moreover, the

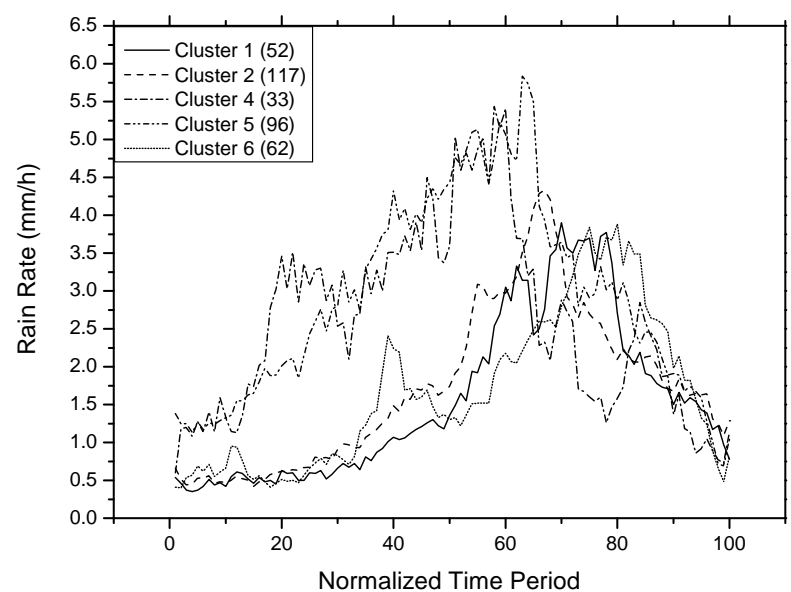

Fig. 5. Five of the six rainfall temporal series (normalized to 100 time units) obtained from a hierarchical clustering analysis of the 365 rain gauge data during 1989-2002. Number in parentheses gives number of members in each of the clusters.

peak rain rate in the former pattern is much higher. Detailed comparison between clusters 4 and 5 also reveals that cluster 4 contains another peak rain rate early in the period (at around the 20th normalized time unit). Cluster 3 is not shown in Fig. 5 because of its small member number and its profile consists of a single peak at the beginning of the entire time period (to be explained later).

Examination of the location of the station members within each cluster shows that they are also grouped geographically (Fig. 6). Clusters 1 and 2 account for the rainfall profiles at the plain and lower-altitude areas west of the CMR. Cluster 3 has only 5 members and they are all located at high altitudes (see topography in Fig. 1). Orographic lifting effect plays a comparatively more crucial role for the large rainfall amount recorded in these stations than in other clusters, and therefore these 5 members are not combined into other clusters during the analysis.

Clusters 4 and 5 possess similar temporal profiles, and they respectively account for the rainfall patterns at the east coast and northeastern part of Taiwan. Finally, members in cluster 6 all concentrate at the southwestern side of Taiwan. Generally speaking, the temporal rainfall profiles classified according to the clustering analysis procedure are indeed consistent with the track types of TCs affecting Taiwan. Most of the TCs approached Taiwan from the east (the E-W members) or from the south (the S-N members that formed in the South China Sea or recurved from the Philippines). Thus, the east coast of Taiwan is often the first region to receive heavy rainfall, which explains the first peak rain rate in the profile of cluster 4. As most of the TCs in the WNP travel northwestward, those approaching the Taiwan area would bring rain to the northeastern Taiwan where the cluster- 5 members situate. The peak rain rate for the members in clusters 1,2 


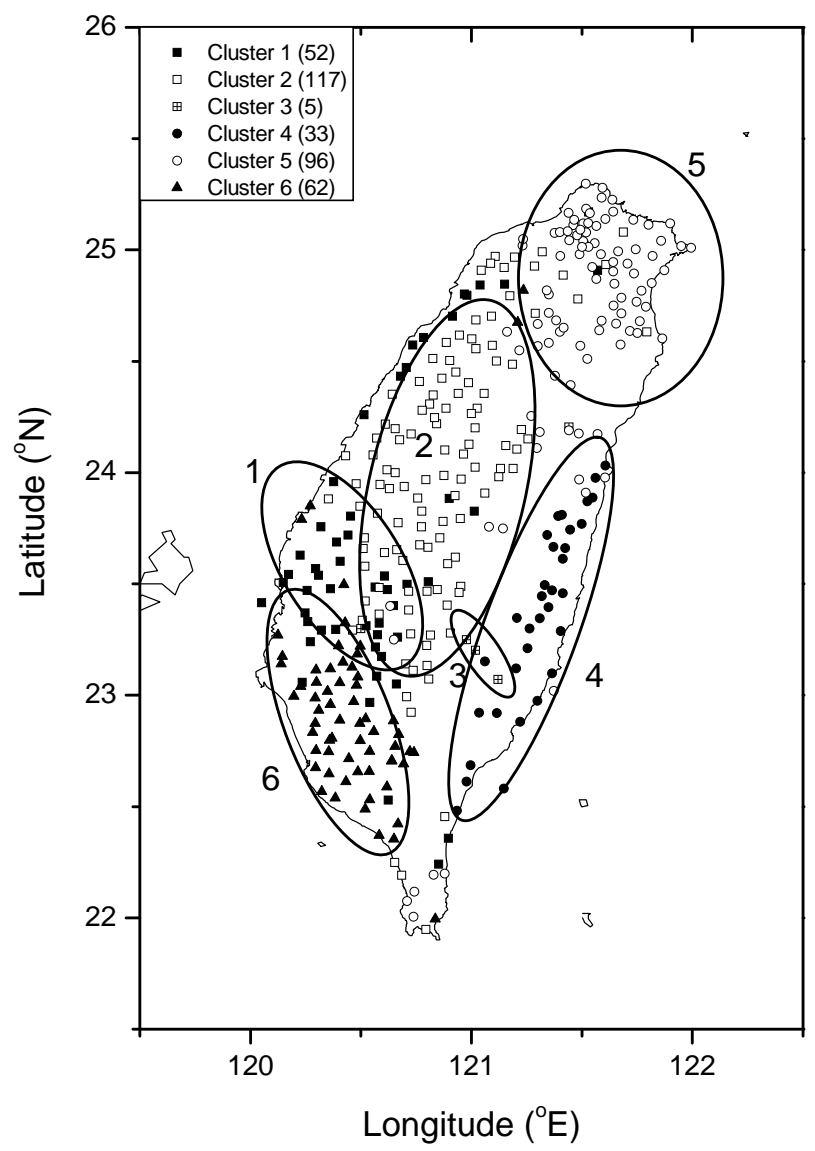

Fig. 6. Geographic locations of rain gauge members of the six clusters.

and 6 all occur later when the landfalling TCs pass through the CMR of Taiwan or when the northward traveling TCs move to higher latitudes.

\subsection{Monsoon-related rainfall patterns}

Besides the internal distribution of convection within a TC and Taiwan's topographic influence, the rainfall pattern when a TC affects the Taiwan area is frequently modified by the large-scale monsoonal flow. Sometimes, the rainfall amount and distribution change dramatically that causes much forecast difficulty. For instance, two typical scenarios have been discussed widely in the Taiwan meteorological community. The first one is the warm, moist southwesterly flow during the summer monsoon period induced by TC circulation, which usually occurs when the TC center is north of Taiwan. Due to the abundant moisture supply, the rainfall amount can be enhanced substantially. A well-known example that occurred recently is Typhoon Mindulle (2004) that made landfall at the east coat of Taiwan around 12:00 UTC 1 July, stayed over land for about $30 \mathrm{~h}$ and then moved out to the ocean again around 06:00 UTC 2 July (Fig. 7a). When the center of Mindulle was just north of Taiwan, the conver- gence of its circulation with the monsoonal southwesterlies induced severe convection over the southwestern part of Taiwan and brought heavy rain there. When Mindulle moved further northward, its effect to the Taiwan area decreased but strong southwesterlies still persisted. These southwesterlies impinged on the CMR and the orographic-lifting effect caused more torrential rain (Lee et al., 2005). As a consequence, the accumulated rainfall during $2-4$ July covered the entire southwestern part of Taiwan as well as some mountainous regions.

There were some historical cases of which torrential rain was closely related to the enhanced southwesterlies. Examples are Typhoon Ellen (1959), Agnes (1981), Doug (1994) and Kai-Tak (2000). In order to examine the characteristic rain pattern associated with these TCs, composite rain distributions for the three recent cases of Doug, Kai-Tak and Mindulle, which have similar track type when they passed through northeastern Taiwan, are calculated. The composite period for each TC is determined by examining the average low-level $(925-\mathrm{hPa})$ meridional wind component in a region $\left(110^{\circ}-120^{\circ} \mathrm{E}, 10^{\circ}-20^{\circ} \mathrm{N}\right)$ southwest of Taiwan, and the two days with substantial increase in wind speed is chosen. In the day-1 composite, rainfall concentrates at the eastern side of Taiwan (Fig. 7b) that is mainly associated with the TC circulation. In day 2 when the TC center moves further northward, convergence of TC circulation with the southwesterlies shifts the rain to the other side of the CMR (Fig. 7c). Variation in these three typhoon cases indeed exist, with Typhoon Doug contributing more rain to northwestern Taiwan and Typhoon Mindulle more to southwestern Taiwan in the day- 2 composite.

Another scenario occurs during the autumn when the warm, moist TC air mass confronts the cold, dry winter monsoonal flow that produces near frontal rainfall to the area. A recent example is Typhoon Xangsane (2000) that was located west of the Philippines at the end of October and then passed through the east coast of Taiwan in early November (Fig. 7d). The high pressure system in mainland China combined with Xangsane's circulation to enhance the northeasterlies in the Taiwan area especially that north of Taiwan. As for the cases with enhanced southwesterlies, two other historical TCs are identified with similar situation as in Typhoon Xangsane, which are Typhoon Seth (1994) and Typhoon Zeb (1998). They all satisfy the following conditions in a 2-day period: (1) a surface frontal system existed north of Taiwan that indicated high pressure system in mainland China, (2) strong northeasterlies were recorded by an island station (Penchiayu, station code 46695 near $122.07^{\circ} \mathrm{E}, 25.63^{\circ} \mathrm{N}$ ) north of Taiwan, and (3) heavy daily rain $(>130 \mathrm{~mm})$ occurred in northern Taiwan. Composite rain distributions are then calculated for these three TC cases. In the day- 1 composite when only the TC circulation was affecting Taiwan, rainfall again concentrates at the eastern side of the CMR (Fig. 7e). Due to the strong convergence between TC circulation and the monsoonal northeasterlies in day 2 , peak rainfall oc- 
(a)

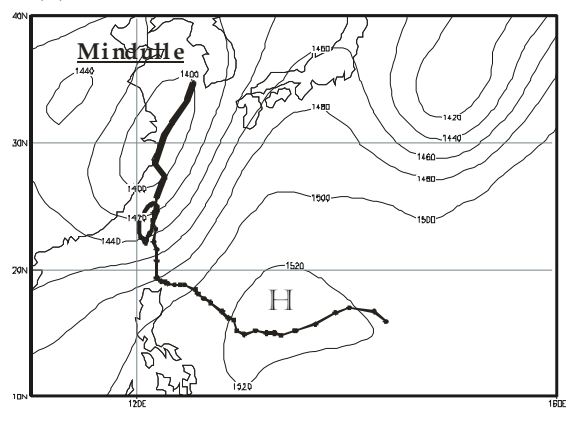

(b)

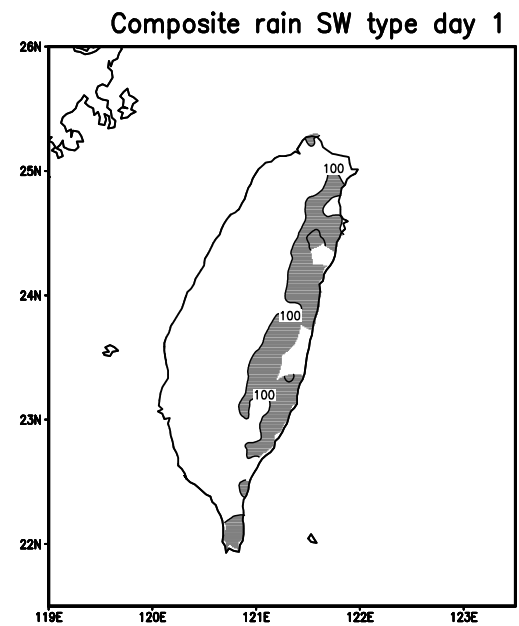

(c)

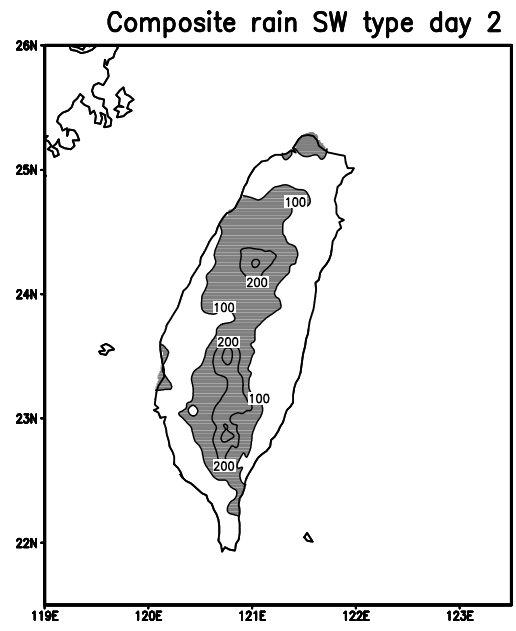

(d)

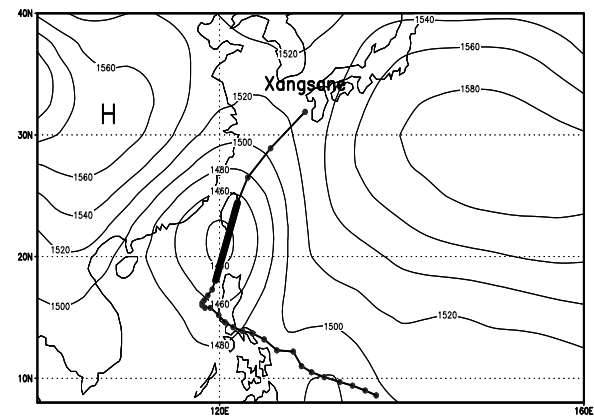

(e)

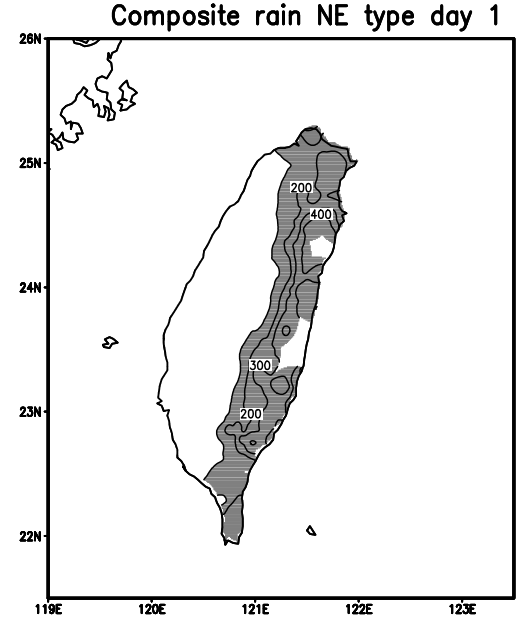

(f)

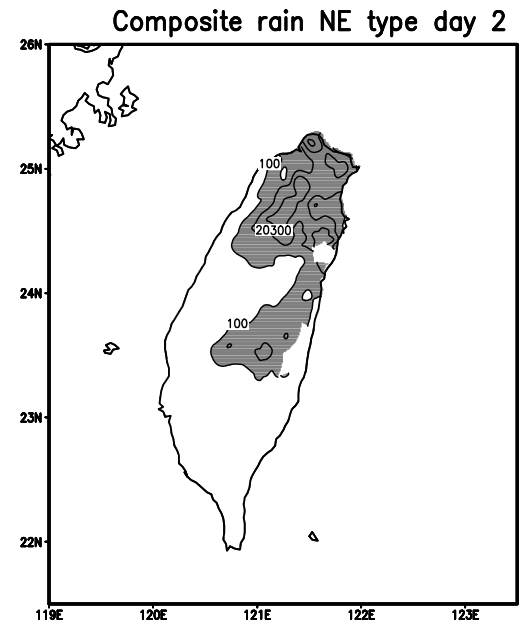

Fig. 7. (a) Best track of Typhoon Mindulle (2004) with 6-hourly positions and mean 850-hPa geopotential heights (unit: m) during the period (07:00 UTC 2 July-12:00 UTC 4 July) when southwesterlies persisted in the region southwest of Taiwan, which is also indicated by the thickened portion of track. (b) Day-1 composite rain distribution for Typhoons Doug (1994), Kaitak (2000) and Mindulle (2004) (unit: $\mathrm{mm}$ ) with amounts over $100 \mathrm{~mm}$ shaded. (c) As in(b) except for day-2 composite for the same typhoons. (d) As in (a) except for Typhoon Xangsane for the period 00:00 UTC 31 October-00:00 UTC 1 November 2000 when northeasterlies persisted in the region north of Taiwan. (e) Day-1 composite rain distribution for Typhoons Seth (1994), Zeb (1998) and Xangsane (2000). (f) As in (e) except for day-2 composite for the same typhoons. See text for selection criteria of the two-day period. 
Table 2. Correlation coefficient $(R)$ with observations and root-mean-square error (RMSE) of CLIPER in three different forecast periods for the developmental database in 1989-2002 and the independent cases in 2003-2004.

\begin{tabular}{lcccc}
\hline & \multicolumn{2}{c}{ Dependent cases (1989-2002) } & \multicolumn{2}{c}{ Independent cases (2003-2004) } \\
\cline { 2 - 5 } & $R$ & RMSE & $R$ & RMSE \\
\hline 3-h Accumulated rainfall & 0.63 & 16.0 & 0.77 & 11.4 \\
6-h Accumulated rainfall & 0.61 & 26.9 & 0.68 & 22.2 \\
24-h Accumulated rainfall & 0.50 & 95.3 & 0.40 & 86.6 \\
\hline
\end{tabular}

curred in northern Taiwan (Fig. 7f) that is in much contrast to the TCs interacting with the summer monsoon.

\section{Climatology-persistence (CLIPER) rainfall predic- tion model}

\subsection{Setup of the model}

The CLIPER model is a simple weighted combination of TC rainfall climatology and persistence for estimating rainfall in the future. The model domain is $118^{\circ}-126^{\circ} \mathrm{E}$ and $19^{\circ}-27^{\circ} \mathrm{N}$ as in that shown in Fig. 3. The strategy used to construct the rainfall climatology here is based on Lee et al. (2006) and different from that in Marks et al. (2002) that developed the R-CLIPER for Atlantic TCs. The latest version of R-CLIPER utilizes rain estimates from the Tropical Rain Measurement Mission (TRMM) Microwave Imager (TMI) and derives storm-centered mean rain rate distribution stratified for different TC intensities. This mean rain rate distribution is azimuthally symmetrical, and when accumulated rain amount is computed along the forecast TC track, the rainfall distribution is also symmetrical with respect to the track. However, when a typhoon is approaching the Taiwan Island, its structure and convection distribution will be greatly affected by Taiwan's topography and highly asymmetric rainfall distribution will likely occur. For example, Lee et al. (2006) showed that the features of TC rainfall in the Taiwan area are closely locked by the topography. Therefore in developing the rainfall CLIPER model for the Taiwan area, the actual climatological rainfall map is used. Whenever an official forecast track from the CWB is issued, it is first spatially interpolated such that hourly positions are available. Then the rainfall database for each of the 365 main-island stations is looked up in turn to obtain the climatology value for a particular TC center position. When this rain amount is accumulated along the forecast TC track, the rain distribution within a certain forecast period (i.e., the climatology component of the CLIPER) is obtained.

Next the persistence component of the CLIPER is determined. Various tests based on maximizing the pattern correlation (correlation coefficient computed for all stations) between CLIPER forecast rain and observed value on the persistence duration indicate that a 3-h period is optimal to project a reasonable short-range rainfall estimate. Since convective timescale is sometimes as short as an order of 2-3 h, application of a longer persistence amount even degrades some of the forecasts. Thus the 3 -h persistence duration is applied to all of the 365 main-island rain stations (i.e., persistence is average rain in the $3 \mathrm{~h}$ before initial forecast time). Then experiments are performed to determine the relative contributions from climatology and persistence in the final rainfall prediction. Evaluation is again based on pattern correlation in 3 -h periods up to $24 \mathrm{~h}$. It is found that the optimal pattern correlation is realized when the ratio of climatology to persistence is $4 / 6(7 / 3)$ in the $0-3-\mathrm{h}(3-6-\mathrm{h})$ time period, and then only climatology is used after $6 \mathrm{~h}$. That is, the CLIPER model can be stated mathematically as $\alpha \times$ climatology $+(1-\alpha) \times$ persistence, in which $\alpha=0.4(\alpha=0.7)$ in the $0-3-\mathrm{h}(3-6-\mathrm{h})$ forecast period and $\alpha$ equals to one otherwise.

\subsection{Performance}

Verification of CLIPER is performed using forecasts with initial times $6 \mathrm{~h}$ apart to ensure independency of cases. Within the model database that consists of cases in 1989-2002, correlation coefficient $(R)$ between CLIPER's forecasts (using the official CWB forecast tracks) and observations at all the 365 rain gauges ranges from 0.63 for 3 -h accumulated rainfall to 0.5 for 24 -h period (Table 2). The corresponding root-mean-square error (RMSE) ranges from $16.0 \mathrm{~mm}$ to $95.3 \mathrm{~mm}$, indicating that the simple combination of climatology and persistence does provide reasonable estimates of rainfall pattern and amount in the short range. The verification for the independent cases in 2003-2004 actually indicates slightly higher correlation coefficient in the short range ( 0.77 for 3 -h and 0.68 for 6 -h forecasts) and lower RMSE for all time periods $(11.4 \mathrm{~mm}$ for $3-\mathrm{h}$ and $86.6 \mathrm{~mm}$ for $24-\mathrm{h}$ forecasts).

Equitable threat score (ETS) is often used to evaluate rain prediction skill that measures the number of forecasts (locations) that match the observed threshold amount (Tuleya et al., 2007). ETS can be written as

$$
\mathrm{ETS}=\left(\mathrm{H}-\mathrm{H}_{\text {random }}\right) /\left(\mathrm{F}+\mathrm{O}-\mathrm{H}-\mathrm{H}_{\text {random }}\right)
$$


where $\mathrm{F}$ and $\mathrm{O}$ are the numbers of forecasts and observations satisfying the threshold criteria, $\mathrm{H}$ is the number of forecasts (locations) that successfully meets the same criteria as the observation. $\mathrm{H}_{\text {random }}[=\mathrm{F} \times \mathrm{O} /(\mathrm{F}+\mathrm{O})]$ is an "equitable" measure that accounts for the random chance that both forecast and observed meet the criteria. It can be seen that for a perfect forecast, $\mathrm{F}=\mathrm{O}=\mathrm{H}$ and $\mathrm{ETS}$ is equal to one. In addition, the bias score (BS) is simply defined as the ratio of $\mathrm{F}$ to $\mathrm{O}$ that indicates the degree of underestimation/overestimation. $\mathrm{BS}$ is equal to one for no-bias forecast.

ETS is computed to examine the ability of CLIPER to predict rainfall of a certain amount. Four rain thresholds of $50 \mathrm{~mm}, 130 \mathrm{~mm}, 200 \mathrm{~mm}$ and $350 \mathrm{~mm}$ in $24 \mathrm{~h}$ are considered according to the definition of different categories of heavy rainfall in the CWB. There are various ways of calculating the ETS in a certain area. If all the 365 rain stations are considered as independent cases in counting the values of $F$, $\mathrm{O}$ and $\mathrm{H}$ for calculating the ETS of 24-h forecast (i.e., spatial distribution of forecast rain is considered), the values of $0.22,0.13,0.08$ and 0.04 are obtained for the above mentioned thresholds respectively. According to the ETS results, the CLIPER developed in this research is comparable with that of R-CLIPER for Atlantic hurricane rainfall (Marchok et al., 2006).

On the other hand, in order to examine the skill of CLIPER in different locations in Taiwan, ETS for each station is also computed (i.e., no spatial distribution of forecast rain is considered but forecast amount is evaluated at a particular location). Note that the number of verification cases during 2003-2004 is 48, which is statistically acceptable for distribution estimation. The following discussions concentrate on these station-wise ETSs computed in different forecast periods.

The ETS averaged over all stations for a threshold of $50 \mathrm{~mm}$ in $24 \mathrm{~h}$ is about 0.24 in the $0-6-\mathrm{h}$ period and drops gradually with increasing forecast periods (Table 3 ). The ETS for 24-h rainfall forecast with the same threshold is about 0.13. These ETS values decrease substantially for higher rainfall thresholds, indicating that CLIPER is unable to estimate the extremely heavy rainfall amount. However, these verification results are quite dependent on TC tracks. If the forecast tracks are perfect (i.e., using the best tracks as inputs to CLIPER), the ETS in the 24-h period for $50 \mathrm{~mm} /$ day threshold increases to 0.22 . The ETS's in other verification periods also increase substantially (except for the $0-3-\mathrm{h}$ and 0-6-h forecasts with 50-mm threshold but the differences are small), indicating that good TC track forecasts are indeed essential for even a statistical model based on climatology like CLIPER.

Moreover, it is also found that the ETSs for individual stations have similar geographic distribution for different forecast periods. The scores based on forecast TC tracks for northwest Taiwan are consistently higher than those in south and southwestern Taiwan, and some have values as high as 0.4-0.5 (Fig. 8 for 24-h forecast, those for shorter-range fore-
Table 3. Average equitable threat score (ETS) for all stations of the CLIPER model when using the operational TC forecast tracks during 2003-2004 as inputs in four different forecast periods and four different rain threshold. The value in parentheses is the corresponding ETS when using the best track as input to the model.

\begin{tabular}{cccc}
\hline $0-3 \mathrm{~h}$ & $0-6 \mathrm{~h}$ & $0-12 \mathrm{~h}$ & $0-24 \mathrm{~h}$ \\
\hline $\begin{array}{l}50 \text {-mm threshold } \\
0.25(0.22) \quad 0.24(0.20)\end{array}$ & $0.19(0.21)$ & $0.13(0.22)$ \\
130-mm threshold & & \\
$0.16(0.19) \quad 0.15(0.16)$ & $0.11(0.14)$ & $0.064(0.12)$ \\
200-mm threshold & & \\
$0.12(0.15) \quad 0.11(0.12)$ & $0.068(0.099)$ & $0.032(0.047)$ \\
$350-\mathrm{mm}$ threshold & & \\
$0.062(0.10) \quad 0.045(0.05)$ & $0.024(0.029)$ & $0.0081(0.0035)$ \\
\hline
\end{tabular}

casts have similar distributions). While the dynamical processes affecting rainfall in the southwestern part of Taiwan are complicated (e.g., track continuity and secondary center due to orographic effect (Liu, 2006), influence from monsoonal flow, etc.), this geographic distribution of ETS may imply that the predictability of TC rainfall in different parts of Taiwan is different, and that skill in forecasting rain in the southwestern area is particularly low.

Examination of the BS indicates that CLIPER's forecasts have no serious bias throughout the 24-h forecast period for rainfall threshold near or below $100 \mathrm{~mm}$ (Table 4) because BS is not far from one. However, for the extremely heavy rainfall thresholds of $200 \mathrm{~mm}$ and $350 \mathrm{~mm}$, BS drops substantially and the bias toward underestimation is obvious. Nevertheless, this model forecast bias is also due partially to errors in track forecast. If best track is used as input to CLIPER, the bias is corrected to a large extent especially for the large rainfall thresholds.

\subsection{Case studies}

Three examples are used to illustrate the performance of CLIPER. The first case is Typhoon Aere (2004) that possessed a northwestward track in the WNP and then took a westward track when it passed by the northern part of Taiwan on 25 August. The 24-h accumulated rainfall valid at 12:00 UTC 25 August concentrated on the windward side of the CMR and there were two maxima: one to the north that received over $1200 \mathrm{~mm}$ of rain and another one to the south that received about $700 \mathrm{~mm}$ of rain (Fig. 9a). Because the track of Typhoon Aere is quite a common westward-moving TC, CLIPER is able to reproduce the location of the rain maxima quite accurately if the best track is used as input (Fig. 9b). However, it can be seen that the forecast accumulated rain is much lower than that observed (percentage 
Table 4. As in Table 2 except for the bias score (BS).

\begin{tabular}{|c|c|c|c|}
\hline $00-03 \mathrm{~h}$ & $00-06 \mathrm{~h}$ & $00-12 \mathrm{~h}$ & $00-24 \mathrm{~h}$ \\
\hline \multicolumn{4}{|c|}{ 50-mm threshold } \\
\hline $0.81(0.79)$ & $0.84(0.84)$ & $0.85(0.94)$ & $0.75(0.99)$ \\
\hline \multicolumn{4}{|c|}{ 130-mm threshold } \\
\hline $0.46(0.54)$ & $0.46(0.50)$ & $0.48(0.56)$ & $0.48(0.63)$ \\
\hline \multicolumn{4}{|c|}{ 200-mm threshold } \\
\hline $0.33(0.47)$ & $0.33(0.37)$ & $0.36(0.37)$ & $0.29(0.34)$ \\
\hline \multicolumn{4}{|c|}{ 350-mm threshold } \\
\hline $0.19(0.25)$ & $0.14(0.16)$ & $0.13(0.10)$ & $0.076(0.052)$ \\
\hline
\end{tabular}

underestimate is $\sim 50 \%$ for the maximum rainfall to the north and $\sim 40 \%$ for that to the south).

Another example is Typhoon Mindulle (2004) already mentioned in Sect. 3.4, for which the effect of monsoonal southwesterly flow is essential in determining the rainfall distribution. Because of active convection embedded in mesoscale systems southwest of Taiwan induced by the convergence between Mindulle's circulation and the monsoonal southwesterly flow on 2nd July (see Liu, 2006), heavy rain occurred at the southwestern plain area of Taiwan (Fig. 9c). Since CLIPER takes no consideration at all of this kind of environmental factor, its forecast only accounts for a TC making landfall at the east coast and thus the forecast accumulated rain on the same day concentrates at the east side of the island (Fig. 9d).

Nevertheless, for TCs with moderate rainfall and less influence from monsoonal flow or mesoscale systems CLIPER usually estimates both the rainfall distribution and amount quite well, which is illustrated by the third example of Typhoon Longwang (2005) that made landfall at central Taiwan in early October. The 24-h observed rainfall during the period when Longwang passed through Taiwan concentrates on the right hand side of the track that has maximum rainfall of about 500-600 mm (Fig. 9e). The CLIPER forecast rainfall has about the same location of maximum and similar accumulated rain (Fig. 9f), and the estimation also includes a large area of moderate rain at southwestern Taiwan that is also found in the observation.

\subsection{Future directions}

Despite the limitations and weaknesses of CLIPER depicted by verification and the case studies above, the model has been applied in CWB and NCDR for real-time TC rainfall estimation in recent years. In view of its skill characteristics as depicted in the evaluation results in Sect. 4.2, focuses of its application are in rain amount in the short range (within $6 \mathrm{~h}$ ) and rain distribution in the 24-h forecast range. In order to further improve TC quantitative precipitation forecast, a

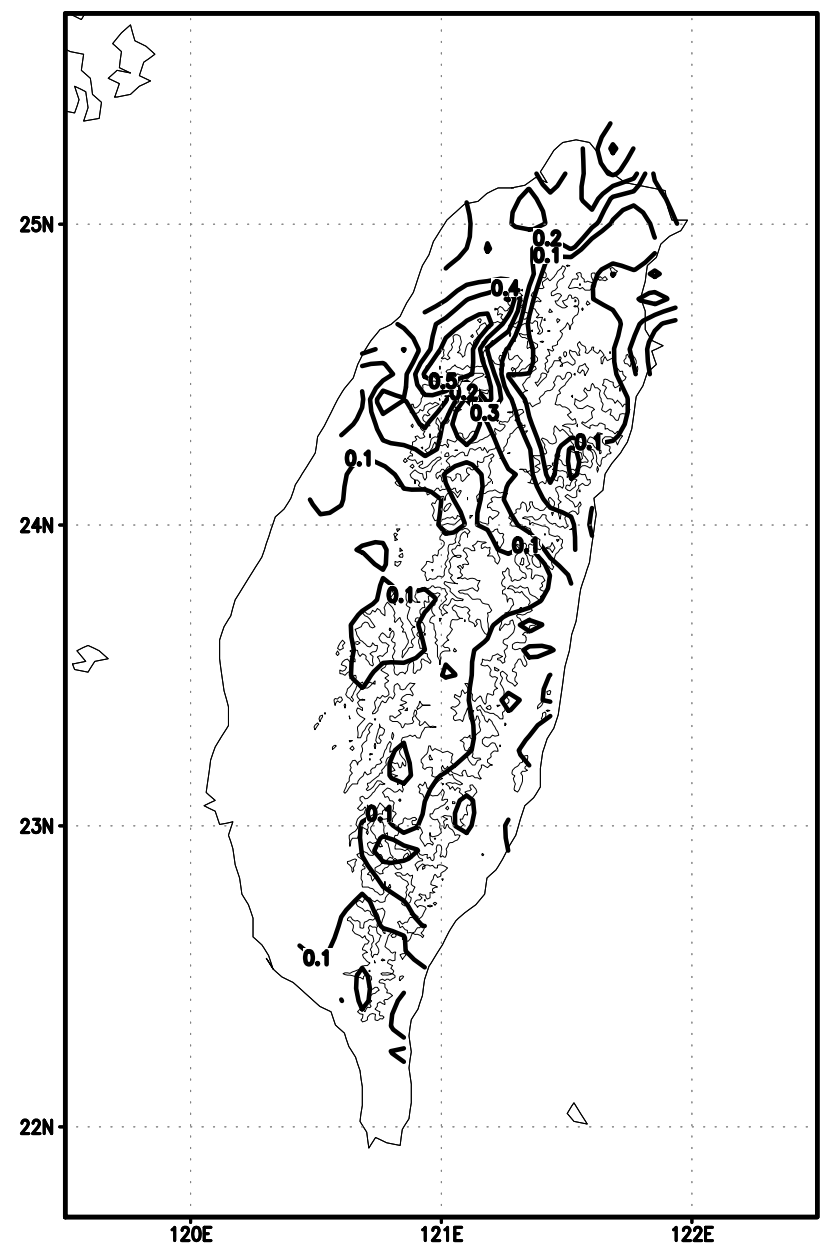

Fig. 8. Geographic distribution of the equitable threat score with a $50 \mathrm{~mm}$ threshold for 24-h CLIPER forecasts using operational forecast tracks.

more generalized statistical TC rainfall forecast model will be developed that not only accounts for climatology and persistence but other factors that may modify the rainfall distribution as well. The statistical model is based on multiple regressions, and additional predictors that include the structure parameters of a TC (e.g., size and intensity) and possibly other factors derived from synoptic environment. The relative contribution from these factors to the final forecast can also reveal the essential physical processes determining the rainfall amount and distribution.

\section{Summary and discussion}

In summary, the characteristics of TC rainfall in the Taiwan area is studied through various statistical analyses of data in the period 1989-2002 from the 371 automatic rain gauges on the island. In spite of the small size of Taiwan, several characteristic rainfall temporal profiles with different times 
(a)

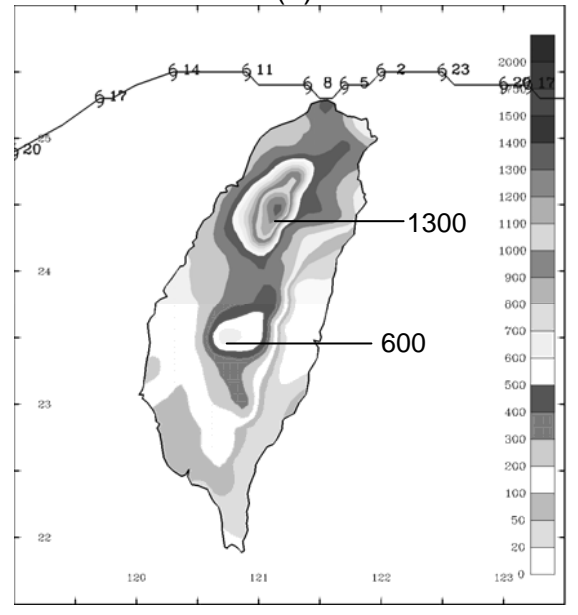

(c)

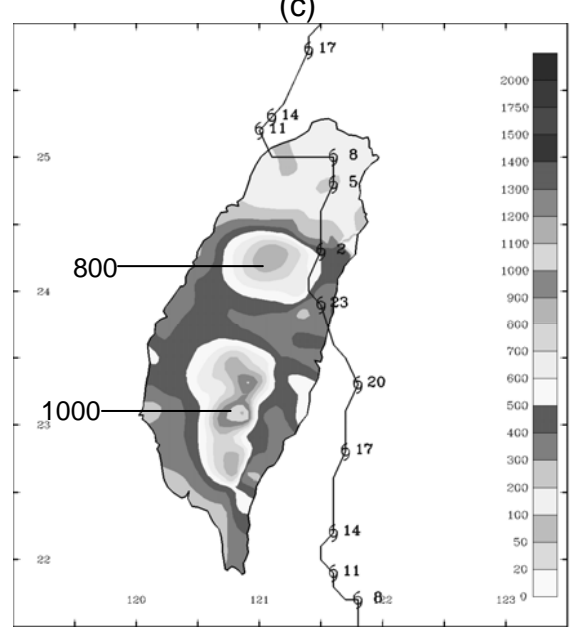

(e)

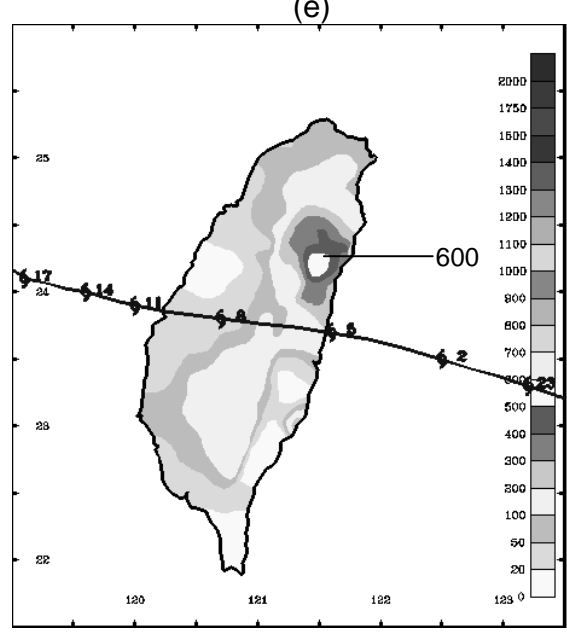

(b)

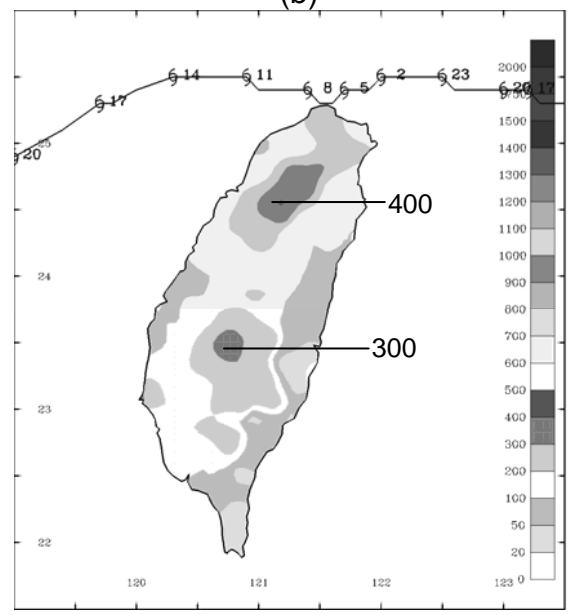

(d)

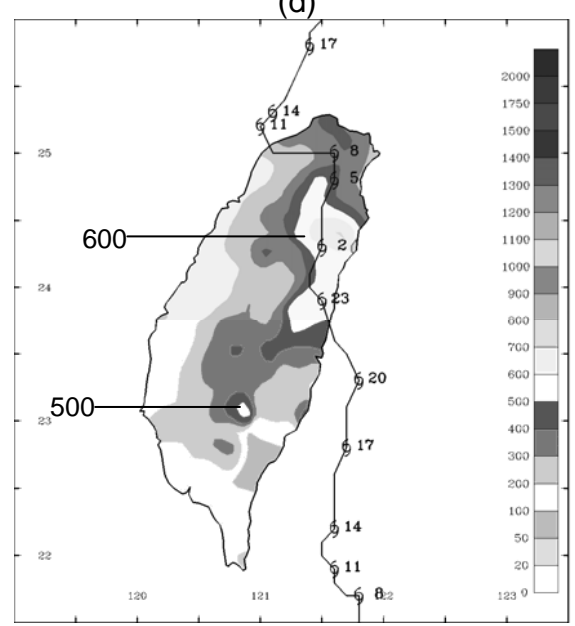

(f)

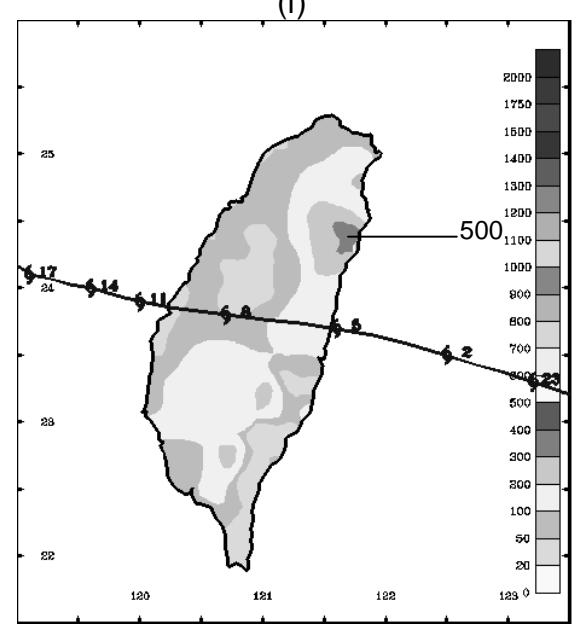

Fig. 9. (a) Observed and (b) CLIPER forecast 24-h accumulated rainfall (unit: mm) for Typhoon Aere (2004) valid at 12:00 UTC 25 August. (c) and (d) as in (a) and (b) except for Typhoon Mindulle (2004) valid at 00:00 UTC 2 July. (e) and (f) as in (a) and (b) except for Typhoon Longwang (2005) valid at 03:00 UTC 2 Oct. The regions with maximum values are labeled. 
of occurrence of rain maximum are identified based on objective clustering analysis. These temporal profiles also have a particular geographic distribution that should be determined by the different impact directions of the TCs.

The spatial characteristics of TC rainfall is studied by establishing corresponding rainfall climatology in a grid covering the Taiwan area. The average rainfall distribution when a TC center is at a particular position relative to Taiwan can easily be extracted from this climatological database. An immediate application of this database is the development of a climatology-persistence (CLIPER) TC rainfall model. By optimizing the correlation coefficients between forecasts and observations, the respective weightings of climatology and persistence are determined for forecasts up to $24 \mathrm{~h}$. Verification results using independent cases in 2003-2004 show that CLIPER can usually reproduce a reasonable rainfall distribution for forecasts up to $6 \mathrm{~h}$ (with a correlation coefficient between 0.6 and 0.7). However, calculation of equitable threat score and bias score shows that the heavy rainfall events (those with 24-h accumulated rainfall over $100 \mathrm{~mm}$ ) are seriously underestimated. One of the major reasons for this underestimation is that CLIPER takes no consideration at all of the TC structure and synoptic-scale environmental factors. Therefore, these factors will be taken into account when developing a more generalized statistical TC rainfall model.

Another important factor that affects TC rainfall in the Taiwan area is its orographic effect. Due to the CMR with elevation up to $3 \mathrm{~km}$, the convection structure and rainfall pattern of all TCs approaching the area will be modified by the CMR to a certain degree. Since the orographic effect occurred in all historical cases, the climatology rainfall value already accounts for the effect partially. To further improve the CLIPER forecast in this aspect, the model output has to be systematically corrected according to the relative importance of topography for TCs with different tracks and structures. Findings of research in this direction will be reported in a later paper.

Acknowledgements. Some of the data processing in this study was performed by A.-H. Wang and C.-T. Weng of the Meteorology Division, National Science and Technology Center for Disaster Reduction, Taiwan. This research is partially supported by the National Science Council of Taiwan under grant NSC 94-2625-Z002-015.

Edited by: K.-T. Chang

Reviewed by: H.-J. Chen and another anonymous referee

\section{References}

Barnes, S. L.: Mesoscale objective analysis using weighted timeseries observations, NOAA Tech. Memo., ERL NSSL-62, National Severe Storms Lab., Norman, OK, 60 pp. (NTISCOM-7310781), 1973.

Chan, J. C. L., Liu, K. S., Ching, S. E., and Lai, E. S. T.: Asymmetric distribution of convection associated with tropical cyclones making landfall along the South China coast, Mon. Weather Rev., 132, 2410-2420, 2004.

Chang, C. P., Yeh, T. C., and Chen, J. M.: Effects of terrain on the surface structure of typhoons over Taiwan, Mon. Weather Rev., 121, 734-752, 1993.

Chiao, S. and Lin, Y. L.: Numerical modeling of an orographically enhanced precipitation event associated with tropical storm Rachel over Taiwan, Weather Forecast., 18, 325-344, 2003.

Corbosiero, K. L. and Molinari, J.: The effects of vertical wind shear on the distribution of convection in tropical cyclones, Mon. Weather Rev., 130, 2110-2123, 2002.

Elsberry, R. L.: Achievement of USWRP Hurricane Landfall research goal, Bull. Amer. Meteor. Soc., 86, 643-645, 2005.

Lee, C. S., Lin, L. Y., Cheung, K. K. W., Chen, Y. M., and Kuo, H. C.: A study on the heavy rainfall event in Taiwan associated with Typhoon Mindulle (2004) and the accompanied southwesterly flow, Proceedings of Conference on Weather Analysis and Forecasting, Central Weather Bureau, Taiwan, 2005.

Lee, C. S., Huang, L. R., Shen, H. S., and Wang, S. T.: A climatological model for forecasting typhoon rainfall in Taiwan, Nat. Hazards, 37, 87-105, 2006.

Lin, Y. L., Ensley, D. B., and Chiao, S.: Orographic influences on rainfall and track deflection associated with the passage of a tropical cyclone, Mon. Weather Rev., 130, 2929-2950, 2002.

Liu, Y. C.: A study on mesoscale features associated with Typhoon Mindulle (2004) when it was affecting Taiwan, M. Sc., Dissertation, Department of Atmospheric Sciences, National Taiwan University, 136 pp., 2006 (in Chinese, English abstract available).

Lonfat, M., Marks Jr., F. D., and Chen, S. S.: Precipitation distribution in tropical cyclones using the Tropical Rainfall Measuring Mission (TRMM), microwave imager: A global perspective, Mon. Weather Rev., 132, 1645-1660, 2004.

Marchok, T., Rogers, R., and Tuleya, R.: New methods for evaluating rainfall forecasts from operational models for landfalling tropical cyclones, Preprints, 27th Conference on Hurricane and Tropical Meteorology, Monterey, Am. Meteorol. Soc., 9A.1, http://ams.confex.com/ams/pdfpapers/108844.pdf, 2006.

Marks, F. D., Kappler, G., and DeMaria, M.: Development of a tropical cyclone rainfall climatology and persistence (RCLIPER) model, Preprints, 25th Conference Hurricane and Tropical Meteorology, San Diego, Am. Meteorol. Soc., 327-328, 2002.

Tuleya, R. E., DeMaria, M., and Kuligowski, R. J.: Evaluation of GFDL and simple statistical model rainfall forecasts for US landfalling tropical storms, Weather Forecast., 22, 56-70, 2007.

Wu, C. C., Yen, T. H., Kuo, Y. H., and Wang, W.: Rainfall simulation associated with Typhoon Herb (1996) near Taiwan, Part I: The topographic effect, Weather Forecast., 17, 1001-1015, 2002.

Yeh, T. C.: Typhoon rainfall over Taiwan area: The empirical orthogonal function modes and their applications on the rainfall forecasting, Terr. Atmos. Ocean. Sci., 13, 449-468, 2002. 